funds available for research grants by $25 \%$. It will also cut support for space-based scientific instruments by one-third, and reduce support for solar physics and high-energy $\gamma$-ray astronomy.

Researchers in most disciplines, in most parts of the world, have to tighten their belts from time to time. But these reductions are more drastic and sudden than any arm of a competently managed research agency should have to bear.

The funding shortfall arises in part because UK subscriptions to CERN, the European Southern Observatory and the European Space Agency are increasing owing to the weakness of the pound against the euro, and the relative growth of British gross domestic product, on which the United Kingdom's contributions are based.

But the main cause of the gap is the rising operating costs of the Diamond synchrotron light source and a second target for the ISIS neutron source, both sited at the Rutherford Appleton Laboratory in Oxfordshire. The popular facilities, which are used by researchers in disciplines ranging from biomedical research to condensed-matter physics, are projected to cost around $£ 60$ million to operate over the period of the council's plan.

The problem has been looming for some time. But the Department of Innovation, Universities and Skills (DIUS), which oversees the research councils, was only created in June and has been unable to obtain additional funds to ease the STFC's plight. Keith Mason, the council's chief executive, has publicly attributed this to the fact that government officials are insufficiently convinced of the economic value of physicists' and astronomers' work.

It should not always be necessary for scientists to provide a purely economic justification for fundamental research into the nature of the Universe. But that case can be made: this research creates skills and ideas that feed into a stronger society and a stronger economy.

The withdrawal from the linear collider and from Gemini reflect badly on Britain's readiness to stand by international collaborations, and will disappoint partners who had long held the nation and its research councils in high esteem. Moreover, grants are being cut in fields where Britain has traditionally excelled, even as the STFC proposes new projects for which a strong scientific case has not been made - such as a joint robotic Moon mission with NASA.

Both the DIUS and STFC, which was founded from an amalgamation of two research
"Government officials are insufficiently convinced of the economic value of physicists' and astronomers' work." councils only in April, are young organizations and their inability to secure extra funding may reflect their relative lack of proficiency in the ancient art of Whitehall infighting. But it also seems, from Mason's comments, that senior officials at the Treasury do not consider astronomy or particle physics relevant to that department's policy of backing research that will foster business innovation.

Denham has asked a panel chaired by Bill Wakeham, vicechancellor of the University of Southampton, to review the likely impact of the proposed changes and report next spring, and the House of Commons innovation committee is launching its own enquiry into how the shortfall came about. These reviews should find out whether it is possible for particle physics and astronomy grantees to be treated fairly inside a research council whose priority will always be the provision of facilities. They should also explore ways of ensuring that disciplines using facilities such as Diamond pay their fair share of operating costs.

\title{
Welcome Nature Geoscience
}

N ot before time, the world's population is focusing its attention on threats arising from humankind's impacts on its planetary habitat. But underlying whatever abilities we have to mitigate the impacts of habitat change lies the essential ability to understand our planet's structure and dynamics at all levels and on all time-scales.

The slow but steady progress in understanding Earth is the momentous achievement of the geosciences since their foundations were laid well over a century ago. Nature Geoscience is Nature's newest monthly sister journal, and is intended to capture the best of those sciences and serve all of the interested research communities (see http://www.nature.com/ngeo). As with all Nature research journals, this launch in no way dilutes Nature's own commitment to these disciplines.

Launching in January 2008, the journal can be expected to track important research currents. For example, an expanding branch of climate science is the investigation of past analogues for current change, such as rapid sea-level rise, warm periods, ocean acidification or such crucial links as the coupling between atmospheric carbon dioxide concentrations and global temperatures over geological timescales. Traditionally rooted in geology, palaeoclimate researchers are now interacting more intensively with modellers and with investigators of modern climate.

Solid-Earth scientists are still exploring the implications of the 2004 discovery of the high-pressure phase of the mineral $\mathrm{MgSiO}_{3}$, the post-perovskite that dominates the lowermost mantle, for our understanding of the structure of this region. This discovery affects our understanding of the temperature in the lower mantle and mantle convection, as well as iron and heat exchange between Earth's core and the mantle. All these, in turn, have implications for our reconstructions of Earth's history, the evolution of its core and the geodynamo.

Like all the Nature research journals, Nature Geoscience will also have its informal aspects. The 'Backstory' section, about the hard work that comes before a publishable research paper, will describe, for example, what it takes to reconstruct 15 million years of Arctic ocean circulation, to map the floor of the Arabian Sea or to study an Alaskan glacier. One of these articles will be published on the final page of each printed issue, with additional articles published online each month.

The coming year sees the start of a period of international programmes focusing on our planet, not least the International Year of Planet Earth. The new journal could not arrive at a more auspicious moment. 